\title{
Legenda Penciptaan Teater Boneka Tiongkok dan Persebarannya di Nusantara
}

\author{
Hirwan Kuardhani ${ }^{1}$, C. Bakdi Soemanto, Lono L. Simatupang, dan Timbul Haryono \\ Sekolah Pascasarja Universitas Gadjah Mada Yogyakarta.
}

\begin{abstract}
ABSTRAK
Wayang Cina berkembang pesat di Indonesia. Beberapa legenda Cina berkembang mengikuti berkembangnya wayang tersebut, misalnya: Legenda Madame Li, legenda Chen Ping, dan legenda Yan. Beberapa lagenda tersebut dibawa oleh imigran Cina ke wilayah Indonesia, seperti Marionette, yang dikenal sebagai wayang gantung , yang dikembangkan di sekitar Pontianak dan Singkawang. Marionette disajikan dalam dialek Hakka dan menyajikan legenda Cina. Sementara boneka sarung tangan yang dikenal adalah wayang Potehi, tumbuh di Jawa berasal dari Fujian, awalnya dalam dialek Hokkian. Dalam perjalanannya, Potehi menggunakan bahasa Melayu Rendah yang menjadi bahasa Indonesia. Potehi dan Boneka Gantung (wayang gantung) telah menjadi bagian dari kebudayaan Indonesia. Mereka layak mendapat perhatian lebih dari pemerintah dan masyarakat, terutama pelaku dan pengamat seni.
\end{abstract}

Kata kunci: Wayang Potehi, legenda Cina, marionette, wayang gantung.

\section{ABSTRACT}

The Chinese Puppet Theatre Legend and Its Spreading in Nusantara. Chinese Puppet Theatre is growing rapidly. Some legends followed to rise Chinese Puppet, for example: Legend of Madame Li, legend of Chen Ping, and legend of Yan. Some of them were brought by Chinese immigrants into Indonesian territory, such as Marionette, known as hanging puppet (Wayang gantung), which is developed around Pontianak and Singkawang, West Kalimantan Province. Marionette was performed in Hakka dialects and performed Chinese legend. While the glove puppet known is wayang Potehi, grown in Java, originated from Fujian, was originally in Hokkian dialect. In its journey, Potehi used Low Malay language which became bahasa Indonesia. Potehi and Hanging Puppets(wayang gantung) have become parts of our culture. They deserve more attention from the goverment and public, especially the actors and art observers.

Key words: Chinese Puppet theatre, legend, marionette), Glove Puppet (Potehi/布袋戲))

\section{Pendahuluan.}

Seni pertunjukan mulai berkembang pesat di Tiongkok (China) sejak jaman dahulu, sebelum tarikh Masehi. Pertunjukan-pertunjukan tersebut semula merupakan bagian dari ritual Shamanistik, bentuknya berupa kombinasi dari nyanyian, tari, dan gerak-gerak maknawi. Di samping itu ada pula seni pertunjukan yang hanya berfungsi sebagai hiburan sebagaimana ditunjukkan dalam sebuah lukisan dinding sebuah kuburan di Mixianpropinsi HenanTengah. Pada lukisan tersebut digambarkan sebuah pesta besar, yang mungkin pernah diselenggarakan oleh penghuni kuburan utama semasa hidupnya. Di gambarkan di situ adanya penari, pemain sulap, penari piring dan pemusik ( Soedarsono,2005:7).

Di samping seni pertunjukan yang dilakukan dengan pelaku manusia berkembang pula jenis seni pertunjukan boneka. Seperti diungkapkan Soedarsono (2005:8):
“ ... Pertunjukan boneka bukan hal baru pada masa dinasti Tang, tetapi mulai merebak dan popular ketika dipertunjukkan di pasar-pasar dan di kota-kota. Kaisar Minghuang yang memerintah dari tahun 713-756 senang sekali menonton pertunjukan-pertunjukan boneka di istana bagian dalam..."

Pendapat Xie Zhihong dalam artikelnya $X u$ Zhuchu's Ingious Puppets mengatakan bahwa daerah Zhangzou di Propinsi Fujian terkenal akan pertunjukan bonekanya sejak masa dinasti $\mathrm{Han}$ (206-220 M) dan masa Dinasti Tang (618-907 M), Sedangkan berdasarkan tulisan Xu Chon'an dalam artikelnya berjudul Chinese Hand Puppet Popular All Over The World menuliskan bahwa pertunjukan boneka kelompok Zhangzhou yang tertulis dalam catatan sejarah, mulai mengadakan pertunjukannya pada masa dinasti Jin (265-420 M) (Mastuti, 2008:5)

1 Alamat korespondensi: Program Studi Pengkajian Seni Pertunjukan dan Seni Rupa-UGM, Gedung Lengkung, Jalan Teknika Utara, Pugung, Yogyakarta. HP: 0817463 468. E-mail: kuardhani@gmail.com 


\section{Bentuk Awal Teater Boneka Di Tiongkok (China)}

Bentuk paling awal dari teater boneka China diduga bermula dari patung-patung kecil terbuat dari tanah liat dan kayu, pada prosesi pemakaman , 2000 tahun lalu. Patung-patung kecil dari tanah liat bersama patung-patung kayu, diletakkan disekitar jenazah saat pemakaman. Model seperti ini digunakan pada masa dinasti Zhou(1066-256 SM). Patung-patung terakota yang disertakan dalam pemakaman ditemukan pula di situs makam kaisar Qin (Chin) (Stalberg, 1984:17-19, Yimin \& Junxiang, 1999:133)

Boneka-boneka terakota ini dibuat untuk menggantikan tradisi sebelumnya yang mengharuskan saudara atau keluarga dan pelayan untuk menemani almarhum dalam kematiannya. Boneka-boneka kayu digerakkan oleh seorang dukun dalam upacara tersebut untuk memanggil roh orang yang mati. Setelah memanggil roh dari si Mati dan memasukkan ke dalam patung kayu, maka sang dukun dapat mengontrol kemana roh pergi. Sang dukun akan menakuti roh tentang kehidupan neraka, sehingga roh akan menuju sorga dengan aman (Yimin \& Xiang, 1999: 133135)

Boneka-boneka dari kayu tersebut dalam tata upacara ritual pemakaman di bawah kendali sang dukun(cenayang) bisa berjalan, melompat, dsb nyaris seperti hidup. Hal inilah yang dipercaya bahwa roh si mati sudah masuk ke dalam patung kayu dan siap berjalan menuju sorga. Sampai akhir masa dinasti Han(206-220 M), masih digunakan patung-patung dalam ritual pemakaman yang dapat digerakkan, menari dan menyanyi seakanakan seperti manusia hidup.

Pada musim semi 1979, penggalian di daerah Laixi, propinsi Shadong ditemukan boneka dari kayu dengan ukuran 6 kaki, 2 inci. Boneka tersebut ditemukan di pemakaman dinasti Han Barat, sekitar 107 sebelum masehi. Terbentuk dari 13 potong kayu, dibuat bersendi untuk memberi pergerakkan lutut, pundak dan pinggang. Boneka dapat dibuat duduk, jongkok atau berdiri. Perut dan kaki telah dilengkapi dengan beberapa lubang, yang mana salah satunya berfungsi untuk memasang benang guna mengatur pergerakan dan untuk mengikatkan baju. Sebuah boneka yang sangat mengesankan, memiliki tungkai dan lengan panjang serta ekspresi yang nampak agung, ditambah dengan pakaian, terlihat sebagai hasil karya luar biasa. Ditemukan sebuah tongkat dari perak panjangnya 45 inci didekat boneka. tongkat tersebut digunakan untuk menggerakkan kaki dan tangan boneka. Dipercaya bahwa daerah Shandong, sebagai bagian Negara kuno Qi, merupakan daerah yang terkenal dengan sihir, ahli kimia, dan tukang kayu (Yimin \& Junxiang, 1999: 133-135).

\section{Legenda-Legenda di Seputar Teater BonekaTiongkok (China).}

Legenda muncul atau tercipta karena dorongan manusia untuk mencari jawab atau memperoleh jawaban dari suatu benda, peristiwa, pemandangan alam yang aneh ataupun menawan dll. Fungsi legenda sebagai bagian dari tradisi lisan adalah sumber ilmu, manifestasi dari angan-angan terpendam dsb. Sebagai contoh : di Sumatra Barat terdapat legenda Malin Kundang untuk menjelaskan asal muasal batu di pantai yang mirip kapal kandas, di Jawa Barat ada legenda Sangkuriang untuk menjelaskan keberadaan gunung Tangkuban Perahu, di Jawa Tengah ada legenda Rowo pening untuk menjelaskan keberadaan danau Rawa Pening dan masih banyak lagi.

Di Tiongkok (China) pun legenda dipakai untuk "melogika" berbagai hal sebagai jawabannya, termasuk asal muasal jenis wayang, kemampuan seorang dalang dsb. Terdapat beberapa legenda yang melingkupi beberapa jenis teater boneka China sebagai berikut :

\section{Legenda Selir Li.}

Roh yang dapat bergerak terdapat dalam legenda Selir $L i$ pada masa kaisar Wu, Dinasti Han.Legenda ini dipercaya menjadi cikal bakal teater boneka bayangan (piying) salah satu jenis teater boneka yang akan dibahas di bawah ini. Legenda pada masa dinasti Han ini mengisahkan tentang kepedihan hati kaisar Wukarena kematian selir terkasihnya yakni selir Li. Sang kaisar mencari cara untuk menghidupkan kembali selir Li. Seorang pendeta Tao, bernama ShaoWeng penduduk negara bagianQi sanggup melakukannya. Pada sebuah malam Shao-Weng membentangkan tirai, lilin dan lentera. Ia membuat bentuk perempuan dari kulit binatang. 
Dari balik tirai yang ia bentangkan, dengan sorotan cahaya lilin dan lentera bentuk boneka itu digerakkan. Kaisar yang duduk dalam kegelapan melihat bayangan istri tercintanya yaitu selir Li, muncul dibalik tirai tipis. Hal ini mengurangi kepedihan hati sang Kaisar. Akhirnya setiap malam kaisarWu melihat prosesi bayangan selir Li seolah muncul kembali dari kegelapan.(Jilin, 1988:6)

\section{Legenda Dalang Yan .}

Legenda yang mengisahkan mengenai pertunjukan boneka dan keahlianseorang dalang adalah kisah Dalang Yan yang hidup pada zaman 1000 tahun sebelum masehi. Diceritakan bahwa Dalang Yan adalah seorang yang ahli membuat boneka dan memainkannya dengan begitu trampil. Kemasyuran mengenai keahlian Dalang Yansampai ke telinga Kaisar. DalangYan kemudian diundang ke istana untuk mempertunjukkan kepiawaiannya mendalang. Di hadapan sang Kaisar dalang Yan mempertontonkan keahliannya memainkan boneka. Di tangan sang dalang boneka bergerak, menari bagaikan manusia. Tiba-tiba sang Kaisar melihat salah satu tokoh boneka melirik dan berkedip menggoda salah satu selirnya. Kaisar menjadi marah sekali dan memerintahkan untuk membunuh sang tokoh tersebut. Dalang Yan segera berucap bahwa karena sang penari tersebut adalah "anak lelakinya" maka ia lebih suka melakukan perintah kaisar dengan tangannya sendiri di luar arena. Dalang Yan kemudian membawa boneka tersebut ke luar ruang pertunjukan dan membongkarnya. Sang Kaisar tertegun dan terpesona, ia menyaksikan bahwa tokoh tersebut benar-benar sebuah boneka. Kaisar sangat terkesan dengan bakat dan keahlian dalang Yan dalam membuat dan memainkan bonekanya. Akhirnya kaisar menghadiahkan Sekantong Emas kepada Dalang Yan sebagai penghargaan. (Stalberg, 1984: 18-19)

\section{Legenda Chen Ping.}

Di kisahkan Kaisar Liu Bang pada jaman dinasti Han mengadakan perlawanan terhadap suku nomad yang melakukan penyerbuan di wilayah Barat. Tentara Kaisar Liu Bang dipimpin oleh seorang panglima perang bernama Chen Ping. Beliau adalah seorang jendral yang cerdas dan berwawasan luas. JendralChen Ping mendengar bahwa suku nomad yang memberontak dipimpin oleh istri sang kepala suku Xiong-nu yang terkenal dengan keahliannya dalam strategi perang. Isri kepala suku Xiong-nu tersebut mempunyai kelemahan yakni ia adalah wanita yang sangat pencemburu. Hal ini diketahui oleh jendral Chen Ping. Sang jendral kemudian merencanakan membuat tokoh-tokoh boneka kayu yang cantik dan anggun, dengan ukuran seperti manusia. Panglima Chen Ping kemudian memerintahkan para dalang untuk memainkan boneka-boneka tersebut di atas tembok-tembok kota. Boneka kayu bergerak bagaikan manusia, mereka menari dan menyanyi diiringi suara musik nan merdu. Dari kejauhan istri kepala suku Xiong-nu menyaksikan "para perempuan cantik" berpakaian indah dan anggun menari dengan gemualainya. Ia sangat cemburu, khawatir jika sang suami akan tergoda oleh penari-penari cantik. Jika ia dapat menghancurkan kota, maka para perempuan cantik tersebut akan menjadi tawanan bahkan menawarkan diri pada suaminya untuk ditawan. Akhirnya ia memerintahkan pasukannya untuk mundur dan kembali pulang (Margarreta,dalam Stalberg1984:19)

\section{Legenda Nio Peng Lin.}

Legenda Nio Peng Lin merupakan salah satu versi asal usul Teater Boneka Potehi. Pada akhir dinasti Beng, di kota Coanciu (Quanzhou) yang terletak di sebelah Selatan propinsi Hokkian (Fujian) tersebutlah seorang siucai yakni pelajar yang lulus ujian kesasteraan tingkat pertama bernama Nio Peng Lin (1600-1644). Sang siucai berkali-kali menempuh ujian kesusateraan untuk tingkatan yang lebih tinggi agar dapat menjadi pegawai negeri kota raja di Pakkhia (Beijing),namun selalu gagal. Dalam perjalanan ke Pakkhia (Beijing) guna menempuh ujian untuk kesekian kalinya ia bermalam diperjalanan dan bermimpi bertemu dengan orang tua berambut putih. Dalam mimpinya orang tua berambut putih itu memegangi tangannya dan menuliskan frasa "kong beng kui cingsiang" yang berarti "ketenaran dan kejayaan kembali ke telapak tangan”. Nio Peng Lin mengira mimpi tersebut merupakan petunjuk bahwa ia akan berhasil lulus ujian kali ini. Nio Peng Lin begitu berharap, namun ketika hasil ujian diumumkan ia dinyatakan tidak lulus. Ia pulang kembali ke rumahnya dengan hati sangat 
kecewa. Untuk menghibur kegundahan hatinya ia mulai membuat boneka. Lama kelamaan ia pandai memainkan boneka-boneka itu dan memutuskan untuk menjadi dalang sebagai profesinya seumur hidup. Dengan mengambil berbagai cerita rakyat dan peristiwa sejarah Nio Peng Lin mulai mengarang cerita untuk teater bonekanya. Tidak lama kemudian pertunjukannya termasyur di seluruh Hokkian.(Fujian) Ia baru menyadari makna ucapan orang tua berambut putih dalam mimpinya. (Kwa, 2005 : 18-19)

\section{Legenda Liang Biing Lin.}

Legenda megenai asal mula teater boneka Potehi yag dikenal di Taiwan adalah legenda Liang Biing Lin. Tersebutlah seorang pelajar yang sangat cerdas bernama Liang Biing Lin, bersama temannya yang bernama Liou merekapergi mengikuti ujian pegawai sipil di Kota. Tetapi mereka gagal. Liang Biing Lin mengajak Liou untuk pergi ke Kuil guna berdoa dan menanyakan masa depan mereka. Lioumenolak dan tidak lagi berharap tetapi Liang Biing lin bersikukuh dan sangat yakin bahwa dewa di kuil akan tepat meramalkan nasib masa depan mereka.

Mereka berdua lalu memilih hari baik untuk pergi ke kuil, berpuasa dan menyucikan badan. Mereka menginap di kuil selama 3 malam. Liou tidak merasakan apapun, tetapi Liang Biing Lian bermimpi didatangi seorang tua berambut putih. Orang tua itu memegang tangannya dan berkata” aku tahu ketulusan dan kesungguhanmu, aku akan memberi lima kata di telapak tanganmu." Kakek tua berambut putih tersebut menulis dengan kuas di atas telapak tangan Liang Biing Lian "gongming guei jaang-jong" yang artinya "Sukses dan ketenaran berada di tengah-tengah telapak tangan ini”.

Dengan penuh keyakinan Liang Biing Lian dan Liou pulang dan mengikuti ujian pegawai sipil lagi.Mereka tetap gagal dalam ujian tersebut. Liang Biing Lian putus harapan dan tidak percaya lagi pada Dewa. Ia kembali pulang ke rumah.

Di sebelah rumah Liang Biing Lian tinggal seorang dalang yang mengajar murid-muridnya memainkan pertunjukan boneka tali (Marionette). Liang Biing selalu mengawasi cara sang dalang memainkan tali-tali boneka jika ia ada waktu luang.Ia menyaksikan betapa lihainya dalang tetangganya itu memainkan boneka. Liang Bii kemudian mencoba memainkan boneka dengan telapak tangannya. Ia merasakan bahwa boneka lebih hidup jika dimainkan langsung oleh telapak tangan daripada dengan tali. Ia mendapat ide untuk membuat boneka yang dapat dimainkan dengan telapak tangan.Ia melatihnya dengan giat. Ia kemudian mulai menuliskan lakon-lakon pertunjukannya dan mendalang kemana-mana. Liang Bii Lian menjadi terkenal. Ia baru menyadari arti mimpinya dulu. (Cohen, 1981: 34)

\section{Legenda Empat Narapidana.}

Legenda mengenai asal mula teater boneka Potehi versi lain adalah sebagai berikut : tersebutlah empat orang pesakitan yang ditawan oleh raja Tiu Ongdivonis hukuman mati.Sebelum hukuman mati dilaksanakan salah seorang tawanan mengatakan pada teman-temannya buat apa bersusah hati kalau toh akhirnya mati. Para pesakitan tersebut menghibur diri dengan memanfaatkan barang yang ada di dalam ruang tahanan, yaitu potongan kain bekas, panci dan tutupnya serta bambu dari tangkai sapu. Di saat menanti pelaksanaan hukuman mati empat orang tahanan tersebut berhasil menciptakan permainan. Potongan kain diikat satu ujungnya menyerupai boneka, memiliki kepala, badan dan tangan. Sambil diiringi bunyi-bunyian dari panci dengan tutupnya menyerupai bunyi kecer dan gembreng serta seruling dari tangkai sapu. Permainan keempat terpidana mati tersebut tersiar sampai raja Tiu Ong. Mereka kemudian dipanggil menghadap raja untuk mempertunjukkan permainannya. Melalui boneka kain tersebut keempat narapidana mengkiaskan kebijaksanaan sang Raja. Mereka berhasil menyenangkan dan menggugah hati raja Tiu Ong. Keempat napi tersebut akhirnya dibebaskan. Di luar tahanan, mantan napi tersebut menyebarkan dan mengembangkan permainan asal penjara yang kemudian dikenal sebagai Potehi.( Tiong Gie,2005:22)

\section{Legenda Kasim Wei Zhong Xian.}

Legenda mengisahkan asal mula teater boneka potehi diciptakan oleh seorang terpelajar di Fujian sebagai upaya untuk memprotes kasim Wei Zhong Xian pada abad XVI.(Stalberg, 1984 : 4)

Legenda Selir Li merupakan legenda mengenai asal mula teater Boneka Bayangan ( wayang) bukanlah suatu kisah yang mistis 
atau magis. Sebuah kisah tentang kesedihan hati dan upaya mengobati rasa sedih tersebut, sehingga diciptakanlah bentuk boneka bayangan (wayang). Hal ini berbeda jika dibandingkan dengan asal mula wayang di Jawa misalnya, di mana pertunjukan wayang merupakan satu ritual berhubungan dengan roh nenek moyang yang menjadi "Pepunden" atau yang di puja. Samasama menggunakan wayang untuk berhubungan dengan roh, tetapi di dalam boneka bayangan Tiongkok berlandaskan pada kerinduan yang sangat manusiawi karena kepergian selir yang dicintai. Sementara untuk wayang Jawa merupakan aktivitas ritual untuk berhubungan dengan Roh pelindung kehidupan, dalam hal ini terdapat alasan yang lebih religius. Sehingga pertunjukan wayang di Jawa terkait dan muncul dari sikap religiusitas masyarakat pendukungnya, meskipun pada perkembangannya ada bentuk pertunjukan yang sekuler diperuntukkan semata sebagai hiburan.

Legenda mengenai asal mula Teater Boneka bertangkai, berasal dari taktik pasukan jendral Chen Ping dalam mengelabuhi musuhnya dengan menggunakan banyak boneka kayu yang menyerupai gadis cantik. Legenda ini pun tidak terkait dengan upacara ritual apapun.

Legenda yang menjelaskan asal mula teater boneka Potehi ada tiga versi yang berbeda, yakni versi Empat narapidana, versi kasim dan versi pelajar gagal ujian .Versi legenda Nio Peng Lin dan Liang Biing Lian sesungguhnya sama inti kisahnya. Dari tiga versi legenda tersebut semuanya menceritakan asal mula diciptakannya teater boneka Potehi sebagai peristiwa lumrah terjadi di kehidupan dalam arti manusia biasa yang menciptakan Teater boneka Potehi dan alasan penciptaan punhal yang wajar terjadi. Pada versi empat Narapidana misalnya,diciptakannya bentuk pertunjukan Potehi oleh para Narapidana di saat mereka putus asa menanti hukuman lalu untuk menghibur diri. Para pencipta tersebut adalah orang-orang hukuman, para pesakitan bukan orang mulia atau terpilih oleh dewa. Sedangkan pada versi Nio Peng Lin dan Liang Biing Lian diciptakan oleh pelajar yang gagal ujian. Hal ini memperlihatkan bahwa bentuk boneka Potehi diciptakan oleh orang kebanyakan bukan oleh para dewa atau orang suci sebagai mahluk mitologis, dan niat menciptakkannya bukan didorong suatu hal yang gaib, luar biasa atau hal-hal besar, melainkan untuk menghibur diri.

Dari sudut pandang legenda asal mula pertunjukkan Boneka di Tiongkok tersebut peruntukannya bukan untuk kepentingan ritual. Pertunjukan teater boneka Potehi jauh dari kesan sakral, mistis, ataupun magis.Namun demikian dalam perkembangannya bentuk teater boneka Potehi merupakan bagian pertunjukan upacara keagamaan, termasuk upacara pengusiran roh jahat baik di Tiongkok (China) maupun di Taiwan. Hal ini diduga terkait dengan kebiasaan menyertakan patung boneka kayu dan teraccota(gerabah) ke dalam sebuah kuburan yang kemudian dengan bantuan seorang Cenayang boneka-boneka itu ditempati roh dari si mati agar jalannya dapat dipantau menuju sorga. Pertunjukan teater boneka pun pada perkembangannya sangat erat terkait dengan upacara pengusiran setan atau roh jahat pada upacara pemakaman, upacara keselamatan, menghindari wabah dsb. Upacara pengusiran setan dilakukan pada malam Tahun Baru secara besar-besaran dikenal dengan Fang Xiang Shi. Di dalam upacara tersebut digunakan jubah kulit beruamg oleh orang bertopeng dan empat mata emas pada topengnya yang mewakili kemampuan untuk melihat empat arah. Pada perkembangannya orang bertopeng digantikan pertunjukan boneka.

\section{Jenis-jenis Teater Boneka Di Tiongkok (China)}

Di Negara Tiongkok (China) terdapat beberapa jenis teater Boneka. Merunut bentukbentuk teater boneka di China akan memberikan gambaran mengenai teater boneka Potehi yang dibawa emigran China ke wilayahJawa. Bentuk Teater Boneka di Tiongkok (China) dikelompokkan dalam 2 kelompok besar yaitu : Teater Boneka bayangan (Shadow Puppet) yang disebut Piying, dan teater Boneka (Puppet Teatre)

\section{Piying: Teater Boneka bayangan (Shadow Puppet)}

Teater Boneka bayangan (piying) dipercaya muncul pada abad ke 2 SM. Bermula dari legenda bayangan selir Li maka teater boneka bayangan (piying) mulai terbentuk dan akhirnya menjadi 
pertunjukan teater boneka bayangan (piying) yang menarik.Teater Boneka bayangan (piying) terdapat di banyak daerah di Tiongkok (China) dan mempunyai banyak variasi dan gaya. Tiga gaya yang dapat mewakili boneka bayangan (piying) berada disekitar Luanxian di Popinsi Hebei, Xian di Propinsi Shanxi dan Changshadi Propinsi Hunan (Junxiang dalam Yimin, 1999:165).

Perkembangan Teater boneka bayangan (piying) di Tiongkok (China) 2 kali terhenti. Pertama teater boneka bayangan (piying) ini dilarang oleh pengadilan Qing pada akhir abad ke 19 karena dinyatakan berhubungan dengan gerakan rahasia masyarakat bailianjiao (sekte Teratai Putih) dan kedua karena kekacauan ekonomi yang disebabkan oleh perang TiongkokJepang pada awal abad 20 .(Junxiang dalam Yimin, 1999: 165-170)

Setelah tahun 1950 pemerintahan di daratan utama Tiongkok (China) mulai mereorganisasi dalang-dalang yang tersisa dan membentuk kelompok Teater boneka bayangan (Piying) di banyak daerah yang sejak awal sudah dibiayai Pemerintah.

Teater Boneka bayangan(Piying)mirip wayang kulit di Jawa. Dengan tiga tangkai pengontrol ini dia menggerakan boneka dari belakang layar tipis yang disebut Yincuang. Layar atau Yincuang terbuat dari kain putih dan dibelakangnya diletakkan sumber cahaya.Boneka lalu ditempelkan di layar dan diterangi sumber cahaya di belakangnya, penonton melihat bayangan boneka yang tampak dari sisi layar yang lainnya.

Boneka-boneka terbuat dari kulit keledai, kulit sapi, kulit domba yang transparan/ tembus cahaya. Kebanyakan wajah ditampilkan dalam satu atau tiga per empat profil. Tampilan satu profil disebut Wufenlian (setengah wajah) dimana hanya ada satu alis, satu mata, setengah hidung mulut dan janggut. Profil yang tiga per empat disebut Qifenlian (7-10 dari wajah) menampilkan 2 alis dan mata, hidung dan mulut yang utuh (Jilin, 1988: 10-15).

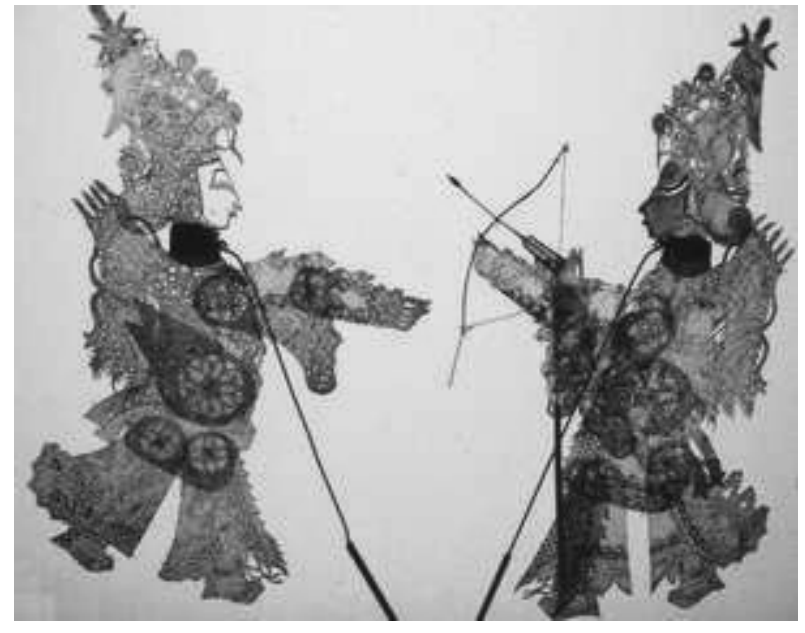

Gambar 1. Piying (Teater boneka bayangan) di Tiongkok (Foto : Repro Hirwan Kuardhani)

\section{Menginspirasi Seorang Tionghoa Peranakan Di Yogyakarta.}

Di Yogyakarta tahun 1925, seorang Tionghoa peranakan bernama Gan ThwanSing menciptakan Wayang kulit China-Jawa. Diduga kuat terinspirasi bentuk Piying dari negera Tiongkok (China). Wayang China-Jawa kreasi Gan Thwan Sing berbahasa Jawa halus seperti pada pertunjukan wayang kulit Jawa, namun ceritanya diambil dari cerita Tiongkok (China) berupa legenda, Mitologi, dan dongeng Tiongkok (China). Misalnya: Rabenipun Raja Thig Jing, San Pek Eng Tay, Lahiripun Li Than Dugi Shik Kong Wuru, Hong Kya Ngenger, dsb.

Diperkirakan ada lebih 40 buah naskah lakon yang diciptakan Gan ThwanSing yang tersebar di berbagai perpustakaan, seperti: FIB-UI(Depok), PDS HB Jassin(Jakarta), Museum Sonobudoyo (Yogyakarta), Taman Siswa (Yogyakarta), Puro Pakualam (Yogyakarta), Museum Mpu Tantular (Surabaya), Universitas Leiden (Belanda) dan Berlin (Jerman)(Mastuti, 2004:3). Naskah tersebut ditulis dalam aksara Jawa . Di dalam pertunjukannya digunakan iringan musik berupa gamelan Jawa.

Hal tersebut diduga karena Gan Thwan Sing lahir dan besar di Yogyakarta, maka beliau sudah sangat familier dengan gamelan Jawa, sementara pengetahuan Ganmengenai bentuk Piying (wayang kulit Tiongkok) diduga berasal dari kakeknya, karena dari sang kakek pula Gan mengenal cerita dongeng dan legenda Tiongkok. Bentuk-bentuk Piying lah yang menginspirasi 
Gan Thwan Sing dalam menciptakan Wayang China-Jawa.

\section{Psiognomi dan atribut Wayang Gan Thwan Sing.}

Psiognomi Piying didugalebih cocok sebagai pelaku lakon-lakon Tiongkok ciptaannya meski dalam pentasnya menggunakan bahasa Jawa. Hal ini berbeda jika $G a n$ membuat wayang berpatokan pada psiognomi wayang kulit Jawa. Bentukbentuk tokoh pada wayang kulit Jawa (wayang Purwa) akan dirasa kurang mewakili sosok tokohtokohnya yang berasal dari Tiongkok (China), Bentuk-bentuk pada wayang kulit Jawa (wayang purwa) sudah baku dalam memerankan tokohtokoh lakon Mahabarata dan Ramayana.

Inspirasi Gan Thwa Sing yang berasaldari Piying jelas terlihat pada contoh wayang pada gambar berikut ini:
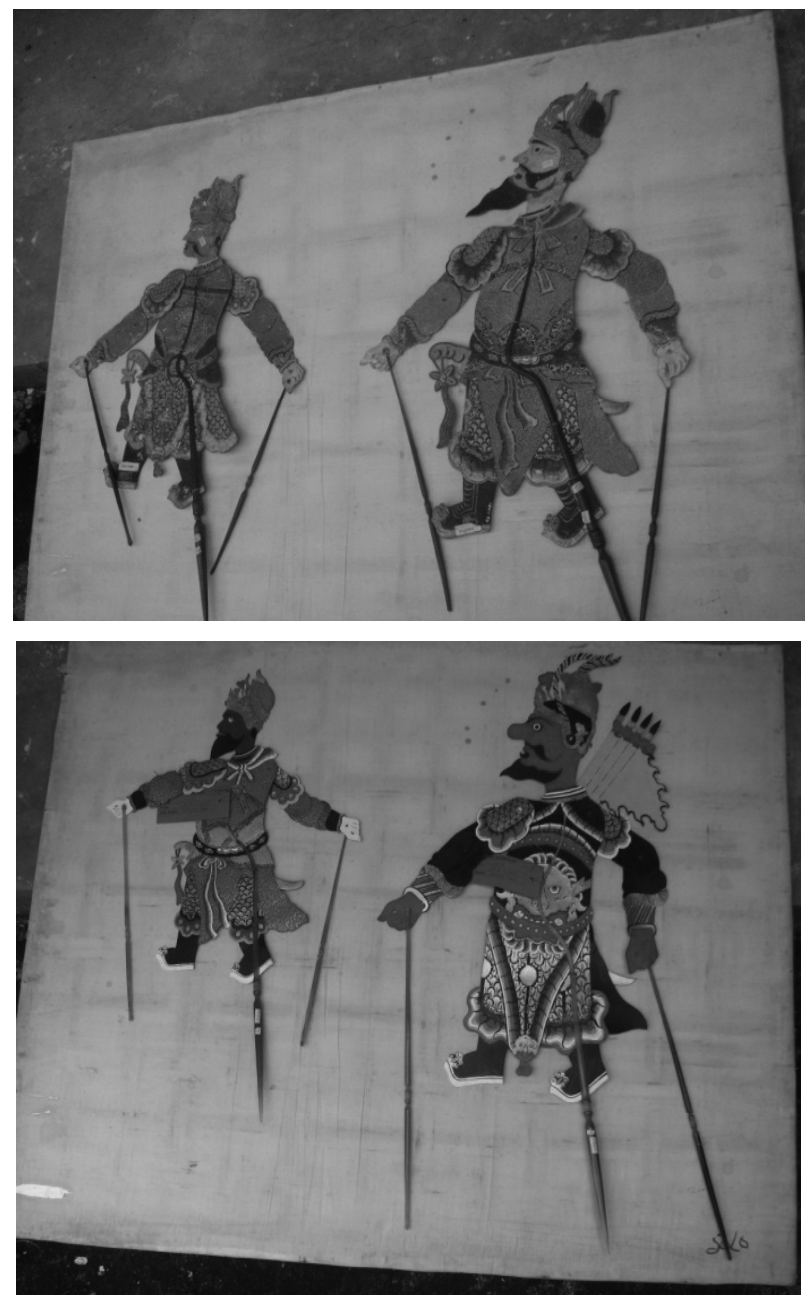

Gambar 2. Tokoh Wayang China-Jawa ciptaan Gan Thwang Sing (Foto: Kasidi)
Pemakaian sepatu ada pada semua bentuk wayang ciptaan Gan Thwang Sing sama seperti Piying dari Tiongkok (China) pada gambar 1 $\mathrm{di}$ atas. Penggunaan senjata berupa bendera yang diletakkan di atas punggung (gambar 2.b ) sama seperti piying (gambar 1.b ). Senjata dalam bentuk bendera lazim dipakai dalam cerita-cerita Tiongkok (China) namun tidak ada dalam cerita Jawa. Bendera berupa umbul-umbul, rontek, panji-panji dsb hanya dipakai sebagai lambang kebesaran sebuah pasukan.

Wayang kulit China -Jawa meskipun diduga terispirasi dari Piying, namun sifatnya personal, dalam arti Piying tidak dikenal secara luas di dalam masyarakat Tionghoa-peranakan di Indonesia khususnya di Jawa, hal ini dikuatkan oleh pernyataan Thio Tiong Gie seorang dalang senior Teater boneka potehi yang tinggal di Semarang, dan juga pernyataan dalang Ki Bejo (Tang Ang) dari Kediri. Sebagai Dalang mereka tidak mengenal jenis wayang yang lain selain wayang atau teater boneka Potehi. Bentuk wayang China (teater boneka bayangan) atau Piying tidak pernahmereka temui.. Menurut ke dua dalang tersebut, Teater boneka Potehi lah yang masuk ke Jawa dan cukup luas dikenal oleh masyarakat Jawa terutama di wilayah Semarang (Jawa Tengah) dan Jawa Timur (Kediri, Jombang, Tuban dan Surabaya).

Nama-nama para tokoh Wayang Gan Thwan Sing masih tetap dalam dialek China Hokkian, namun istilah kepangkatan dan sebutan lainnya telah menggunakan istilah Jawa seperti : Narendra, Pangeran, patih, adipati, senopati, Pandhita, brahmana, radhyan, dyah, abdi, prajurit. Idiom-idiom pedalangan Jawa pun di gunakan seperti adanya janturan,suluk maupun kandha. Di samping itu peralatannyapun sama seperti halnya Wayang kulit Jawa yakni: Kelir, Kambi Kelir, kotak,, Cempala, kepyak, blencong dan sapit blencong. (Mastuti, 2004:6-7).

\section{Yang Chuang Piying: Teater Boneka Bayangan bertubuh Bulat / Teater Boneka Kawat.}

Teater Boneka kawat Chaozhou (Chaozhou Tienzhi Muou) adalah pertunjukan teater boneka di mana boneka yang digunakan merupakan boneka 3 dimensi. Boneka tersebutdioperasikan dengan cara yang hampir sama dengan Teater 
boneka bayangan (piying) dengan 3 tangkai pengontrol, 1 untuk tubuhnya , 2 lainnya utuk tiap lengan boneka).

Awal mulanya dikenal di wilayah Timur Guangdong (Huilei, Haipeng dan Lupeng). Dan kemudian menyebar ke Fujian (wilayah Choan, Yunxiao, Dongshan, Pinghe dan Zhangpo). Orangorang setempat menamainya Zhiyingxi (drama bayangan kertas) atau Yang Chuang Piying ( boneka bayangan bertubuh bulat). Boneka ini secara umum telah dipercaya berkembang dari tradisi Teater boneka bayangan (piying). Selama akhir dinasti Qing (akhir abad ke 19 sampai awal abad 20, dalang Boneka bayangan di Caozou mulai mencari cara baru untuk mengekspresikan kreasi artistik mereka. Hasil dari kreativitas mereka adalah menampilkan boneka dari balik layar kaca bukannya layar kertas seperti yang biasa ada pada teater boneka bayangan (piying). (Yeh, 1986: 88)

\section{Shoutuojingxi: Teater boneka bertangkai (Rod Pupett)}

Teater boneka bertangkai yang berasal dari Guangdong awalnya disebut Shoutuojingxi (kesenian Beijing yang dipegang dengan tangan). Selama akhir Abad ke -19 Opera dari Kanton dilarang oleh pengadilan Qing karena peristiwa pemberontakan Taiping di mana seorang penyanyi dari Kanton yang bernama $L i$ Wenmao ikut serta dalam pemberontakan tsb. Pemerintah tetap melarang opera Kanton meskipun pemberontakan Taiping gagal. Agar opera ini tetap bertahan, para penyanyi opera dari Kanton yang ada di Guangdong tampil dengan nama : Jingxi.( Yeh, 1986: 83). Teater boneka bertangkai ini sama dengan opera Kanton, hanya berbeda dalam hal aktornya. Tetaer Boneka bertangkai menggunakan aktor boneka sedangkan opera Kanton menggunakan aktor manusia.

Boneka bertangkai dari Kanton ini dibagi dalam dua Gaya yaitu: pertama, yang ada di daerah Dongguangdan Huizhou,ke duayang adadi daerah Barat Guangdong.Daerah terakhir biasa dijuluki wilayah Xiasifu, yang terdiri dari 4 bagian yaitu : Xinyi, Gaozhou., Maoming, dan Zanjiang. (Yeh, 1986: 83).
Gaya Pertama memiliki jenis boneka dengan kepala yang besar dengan leher pendek (panjangnya sekitar 1 kaki) yang membuat kurang fleksibel gerakan-gerakan kepalanya. Meskipun demikian hal tersebut sangat melelahkan bagi sang Dalang karena dia harus menaikkan lengannya lebih tinggi dari kepalanya ketika sedang mendalang dan selama pertunjukan, agar penonton dapat melihat bonekanya.

Gaya ke dua, boneka dari daerah barat Guangdong (wilayah Xiasifu) mempunyai proporsi lebih baik dan mempunyai leher sepanjang, tiga kaki sehingga dalang tidak terlalu lelah. Tapi jenis teater boneka yang kedua ini mempunyai gerakan kepala lebih kaku karena perpanjangan leher.

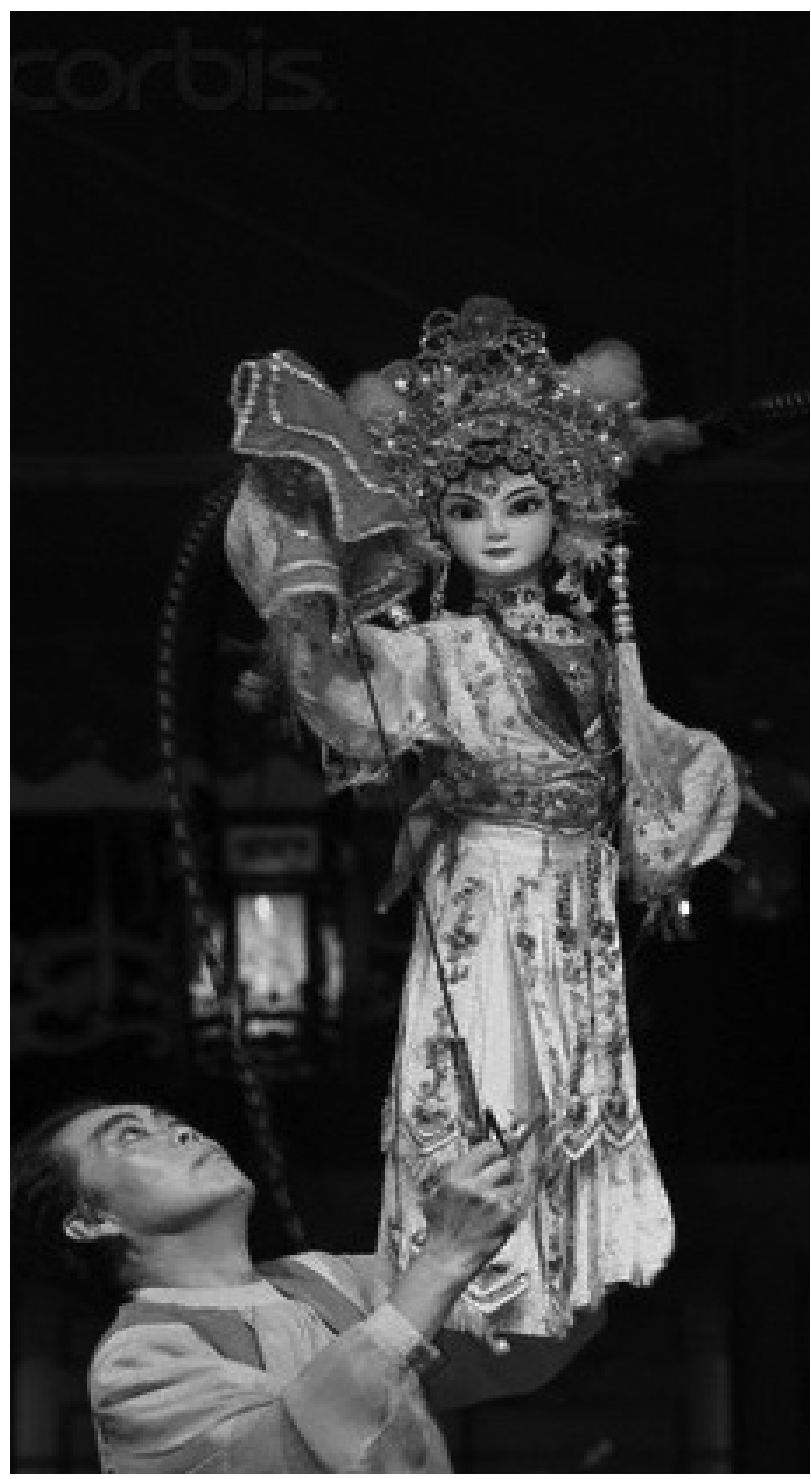

Gambar 3. Dalang memainkan boneka bertangkai jenis besar (Foto : Hirwan Kuardhani). 


\section{Kuileixi: Teater Boneka Tali (String Pupett/ marionett)}

String Puppet atau marionett adalah boneka yang digerakkan dengan tali. Di Tiongkok (China) "tixian Muou" juga disebut"Xuansi Muou" atau "Qianxian Muou" Di tempat dimana bahasa Minnan dipakai, boneka tali biasa disebut dengan "Kuileixi", Xianxi, Jialixi atau dipakai dalam sandiwara tentang cerita budha Maulgalayana (mullian) Mullian Jiali. Istilah Jiali berhubungan dengan upacara atau kegiatan ritual seperti pernikahan, pemakaman, peringatan dewa-dewa setempat atau penyelesaian candi-candi dimana perrtunjukan boneka tali harus ada dan tampil diantara jenis pertunjukan teater manusia yang lain.( Yeh, 1986: 85)

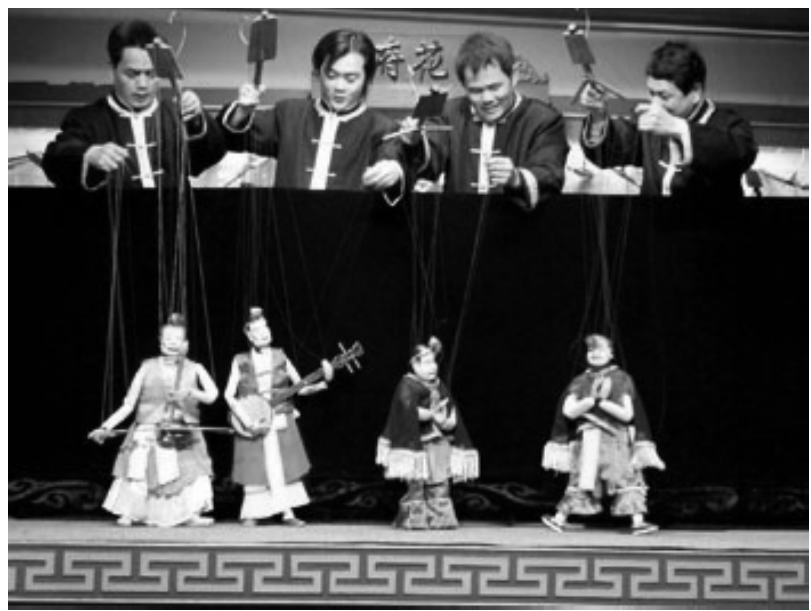

Gambar 5. Kuileixi (Boneka Tali/Marionett) (Foto: repro Hirwan Kuardhani)

\section{Persebarannya ke Kalimantan Barat.}

Jenis teater boneka tali (kuileixi) inilah yang menyebar ke wilayah Kalimantan Barat, utamanya di kota Pontianak, Sambas, Singkawang dan sekitarnya. Di Wilayah tersebut boneka tali (kuileixi) disebut Wayang Gantung. Biasa dipentaskan pada perayaan hari besar Tionghoa di wilayah kota-kota tersebut seperti hari raya Imlek, Cap Go Meh, hari raya Tang Chie dsb. Wayang gantung memakai bahasa Khek (Hakka) baik dalam nyanyian maupun dialog tokoh-tokohnya.

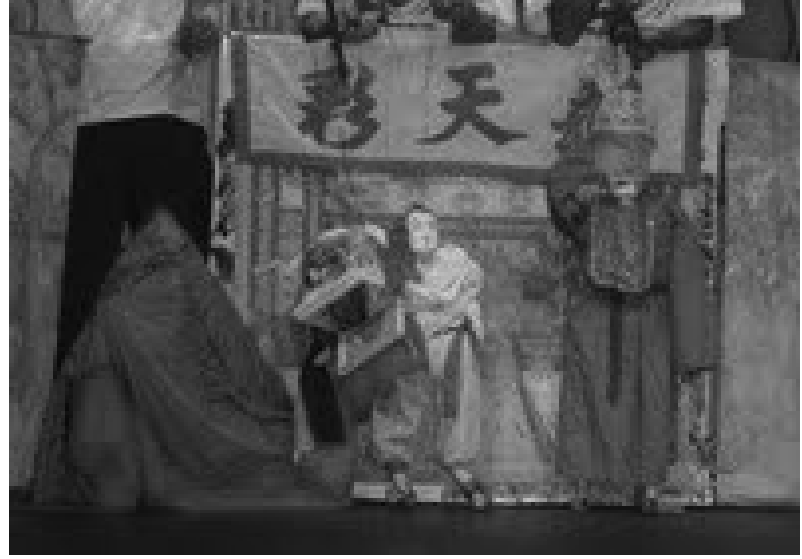

Gambar 6. Wayang Gantung di Kalimanatan Barat (Foto Dinas Pariwisata Singkawang).

\section{Teater Boneka Potehi (Budaxi/ 布袋戲) Dari Fujian Selatan.}

Fujian merupakan pusat pedalangan China khususnya teater boneka sarung tangan atau Potehi (Pouw Tay Hie). Boneka bentuk sarung tangan dalam bahasa Inggris dikenal dengan nama Glove Puppetry atau Hand Puppetry, Palm Theatre, dalam bahasa Mandarin bahasa nasional Tiongkok disebut Budaixi juga dikenal sebagai budai mu'ouxi, shoucao kuileixi, shoudaikuileixi,zh ngzh ngxì, xiaolong, zhangzhong Muou,Zhihuaxi, Zhitou Muouxi (yang berarti pertunjukan jari atau pertunjukan boneka jari).

Di China Selatan Teater Boneka sarung tangan atau Kantong tangan di wariskan secara turun temurun, dari generasi ke generasi. Pertunjukan di wilayah Fujian ini sangat dikenal dengan gaya dari Quanzhou dan Zhangzhou, yang dianggap paling mewakili dari tradisi teater ini. Boneka bentuk sarung tangan memiliki tubuh baju yang berlubang dan lentur sehingga dapat menyesuaikan tangan si dalang dan jarijarinya pas ke kepala dan lengan untuk bergerak Kepala boneka terbuat dari kayu kamper atau sejenisnya, demikian pulatangan dan kaki boneka. Orang Fujian sangat bangga dengan kebudayaan mereka dan menganggap teater boneka mereka lebih dahulu ada dibandingkan teater boneka di 
wilayah Tiongkok (China) Utara. Hal tersebut diperkuat dengan dialek Minnanhua, yaitu salah satu dialek bahasa kuno dari Fujian yang dipakai sebagai bahasa dalam karya-karya seni seperti teater, nyanyian, novel,dan puisi kuno (Stalberg, 1984:27).

Teater boneka Potehi (布袋戲) di Fujian sangat digemari masyarakat karena aksi panggungnya. Tokoh-tokoh dalam teater boneka Potehi (布袋戲) didandani dengan kostum dan riasan (cat) makeup yang sama dengan aktor opera manusia. Demikian pula dengan iringan musik, lagu dan tarian. Sebagai contoh boneka peran tokoh sebagai pahlawan akan mengenakan baju sutra berwarna terang dengan sulaman gambar seekor harimau pada bagian dada dan punggung. Harimau di sini menyimbolkan kekuatan dan keberanian. Topi bulat tinggi menunjukkan pangkat seorang jendral. Make up (cat) wajah berwarna merah menunjukkan keberanian, kegembiraan, optimisme. Warna muka hitam menunjukkan kesetiaan, warna muka putih menunjukkan kelicikan dan atau pengkhianatan.

Masyarakat Fujian sangat menikmati aksiaksi panggung tokoh-tokoh dalam teater boneka Potehi (布袋戲), terutama aksi-aksi dan gerakan seni akrobatik dan beladiri yang tangkas. Dalangdalang dari Fujian terkenal dalam memainkan boneka harimau dan kuda. Kedua sosok binatang itu tampak nyaris seperti "hidup". Lakon "Lei Wanchung MelawanMacan" merupakan lakon yang sangat memasyarakat dan digemari di Fujian Selatan. Lakon ini mengisahkanseorang pelajar sedang dalam perjalanan menuju kota raja Untuk mengikuti ujian pamong praja. Ia disertai seorang pelayan setia.Di tengah perjalanan sang pelajar bersama pelayannya menginap disebuah rumah penginapan. Secara tak sengaja sang pelayan mendengar bahwa pengawal penginapan hendak merampok tuannya yakni si pelajar. Segera pelayan memperingatkan tuannya untuk menyelamatkan diri.Saat itu bersamaan dengan munculnya si pahlawan Lei Wanchungyang tiba di penginapan dalam rangka mencari macan yang tengah meneror wilayah tersebut. Setelah berhasil menemukan macan dan mengalahkannya dalam perkelahian yang seru Lei wanchung bertempur melawan 3 orang penjaga penginapan yang jahat. Bersama keponakannya Lei Wanchung berhasil menyelamatkan sang pelajar dan pelayannya dari gangguan jahat tiga orang penjaga penginapan beserta antek-anteknya.

Lakon di atas membutuhkan keahlian istimewa dari Sehu (dalang Potehi di Jawa) teater boneka Sarung tangan (Potehi (布袋戲)) dari Fujian. Hal ini tidak saja mencakup efek kemampuan bela diri, akrobatik tetapi juga efek "hidup" dari boneka macan, gerakan-gerakan lamban sepoyongan dari Lei Wanchung si pahlawan mabuk. Peran macan sangat terkenal, gerakan ekor yang mengibas-ibas lalu ketika memutar badan memperlihatkan kekuatannya, gerakan menggaruk-garuk, tersengal-sengal ketika kelelahan. Gerakan khas boneka macan di Cina dikembangkan secara khusus oleh kelompok boneka sarung tangan daerah Longxi, di bawah pengajaran seorang dalang ahli Yang Sheng dan kemudian dikembangkan oleh putranya yaitu Yang Feng.Dalang utama dalam teater boneka ini disebut Tou-Shou (tangan pertama) atau Dingshou (tangan atas). Asisten dalang disebut Er-shou (tangan kedua) atau Xia-shou ( tangan bawah) atau $Z$ hu-shou (tangan pembantu).

Selama pertunjukkan sebuah lakon seorang dalang dapat memainkan 5-6 tokoh beserta gerakan dan peran suaranya. Lazimnya dalang utama atau sang tangan pertama memainkan tokoh-tokoh utama dari lakon yang dimainkan tersebut. Dalang pembantu (er-shou) biasanya masih magang atau masih belajar, maka hanya memainkan peran-peran kecil dan tidak berdialog ataupun melagukan nyanyian. Ia hanya membantu gerakan saja.

Pembelajaran menjadi dalang utama bagi seorang calon dalang tidaklahmudah. Seorang pemuda yang akan menjadi dalang harus melewati masa-masa sulit, latihan keras selama 3 tahun empat bulan secara tradisional. (Semacam nyantrik di Jawa). Murid yang nyantrik di tempat sang guru harus melakukan pekerjaan-pekerjaan sehari-hari secara rutin di rumah sang guru. Seperti menyapu, membelah kayu, menimba air $\mathrm{d} s \mathrm{~b}$. Di samping itu tentu saja latihan keras harus dilaluinya.

Dalang-dalang ahli teater boneka Potehi (布 袋戲) dari Fujian telah banyak mengembangkan teknik pertunjukan yang menarik. Untuk mencapai keahlian tingkat para dalang senior maka seorang murid harus tahan menderita. Jikalau 
boneka jenis lain seperti Boneka tali (Marrionet) memakai tali sebagai pengontrol gerak boneka, Boneka bertangkai memakai tangkai atau bilah untuk pengontrol maka teater boneka Potehi (布 袋戲) langsung dari tangan dan jari jemari sang dalang sebagai pengontrolnya. Sendi-sendi tulang jari jemari dan tangan sang dalang secara langsung menghasilkan bentuk dan gerakan tokoh.

\section{Persebarannya ke Jawa}

Awal kedatangannya di pulau Jawa ada dugaan sekitar abad XVI. Seperti diungkap oleh Timbul Haryono sebagai berikut:

Naskah sastra banyak menyebut tentang pertunjukan wayang. Bahkan menarik untuk disinggung adalah tentang Wayang Cina. Istilah tersebut muncul dalam naskah yang lebih muda seperti Malat dan Nawaruci. Di dalam Nawaruci misalnya dikatakan " anggambuh, amancangah, alalangkaran mwang awayang Cina". Di dalam Malat disebutkan :"amancangah, anggringgit Cina". Hal tersebut menunjukkan bahwa wayang Cina sudah masuk ke Jawa sekitar abad XVI atau XVII (Haryono, 2008: 46).

Wayang China yang dimaksud di sini diduga kuat adalah Potehi karena bentuk bentuk teater bonekajenislainnyadariTiongkoktidak ditemukan bekas-bekasnya. Boneka dari kulit, seperti wayang Purwa, atau jenis bertali (Marrionet), maupun jenis bertangkai tidak dikenal masyarakat Jawa, kebanyakan dari mereka mengenal wayang China adalah Potehi. Hal ini dikuatkan dengan data bahwa kebanyakan emigran Tiongkok yang datang ke Jawa adalah orang-orang Hokkian (Fujian) yang merupakan pemilik pertunjukan teater boneka Potehi. Diduga Teater boneka Potehi merupakan pertunjukan yang dipakai untuk keperluan ritual para emigran Tionghoa dari Hokkian(Fujian) sekaligus merupakan alat hiburan bagi para emigran tersebut.

Shu Ming dalam artikelnya Yajiada Zaoqi Kaifa Yu Huaren (pengembangan Jakarta di Masa Awal dan Masyarakat Tionghoa)menuliskan bahwa pada abad ke 17 teater boneka Potehi sudah populer di kota Batavia dan daerah lain. (Mulyono, 1982:113-117)

\section{Akulturasi Potehi dengan Budaya Jawa.}

Pada generasi awal para dalang Potehi (Sehu) masih menggunakan bahasa Hokkian. Pada perkembangannya sudah tidak lagi memakai bahasa Hokkian melainkan bahasa Melayu rendah. Shu Ming dalam artikelnya Yajiada Zaoqi Kaifa Yu Huarenmengatakan dalam pertunjukan Potehi di kota Batavia (Jakarta) perkenalan jalan cerita dan dialog Potehi serta lakon-lakon Tiongkok Selatan lainnya yang dipentaskan pada pertemuan hari raya atau pekan kelenteng di Jakarta telah diterjemahkan dalam bahasa setempat. Bahasa Setempat yang dimaksud adalah dialek Melayu Jakarta, untuk memenuhi kebutuhan warga peranakan dan pribumi yang tidak paham bahasa Tionghoa atau dialek Tiongkok (Mulyono, 1982:113 dan 117).

Demikian seterusnya teater Boneka Potehi di Jawa menggunakan bahasa Indonesia hingga sekarang. Sehu (dalang) Potehi dewasa ini kebanyakan etnis Jawa yang tentu saja akrab dengan kesenian Wayang Kulit. Hal ini berpengaruh pula pada cara Sehu (dalang) menampilkan dialog tokoh-tokohnya dengan lagu kalimat laiknya seperti dalang wayang kulit Jawa. Beberapa kata atau sebutan diambil dari bahasa Jawa misalkan : Ia sangat marah darahnya "mompal-mompal"(menggelegak), Perawakan Sie Jin Kui gagah "Pideksa" (gagah perkasa),Tio Tik Kui adalah seorang mentri "Dorna " (menteri yang wataknya buruk seperti tokoh Dorna dalam wayang Kulit) dsb.

Sehu Tio Thiong Gie dari Semarang, ketika tengah memainkan lakon Sie Jin Kwi di kota Surabaya, menggubah syairEmpat Musim dari bahasa Hokkian menjadi bahasa Indonesia. Beliaupun menyanyikan beberapa lagu yang tengah populer di Jawa diganti syairnya dalam bahasa Hokkian. Misalnya lagu yang dahulu dipopulerkan kan Waljinah yaitu Walangkekek, Kendal Kaline Wungu, Jangkrik Genggong, digubah syairnya dalam bahasa Hokkian sehingga penonton sangat kenal dengan irama lagunya namun syairnya sudah berubah. Sebuah lagu rakyat yang populer Semanggi Suroboyo pun digubah oleh Sehu Thio Tiong Gie dalam syair Hokkian. Jika pentas di Surabaya ia akan menyanyikan lagu-lagu yang akrap dengan pendengar Surabaya, jika pentas di 
Jakarta ia akan melagukan jali-jaliatau Surilang dalam bahasa Hokkian dsb. Hal ini membuat penonton menjadi senang dan pertunjukan semakin "gayeng" (bhs Ind = Seru).

Di dalam memainkan lakon Potehi para Sehu khususnya Sehu suku Jawa akan menyelipkan parikan-parikan berbahasa Jawa. Seperti halnya pantun, maka parikan berisi sampiran pada baris pertama dan isi pada baris kedua, atau separuh dari parikan berisi sampiran dan separuhnya merupakan isi. Hal ini dapat dicermati Sebagai berikut :

(1). "Kembang turi ketok melok-melok megare sore, tanggane padha alok lek mangan golek dewe dewe".

(Bunga Turi kelihatan jelas mekar di sore hari, tetangga semua ribut berkomentar karena kalau makan harus mencari sendiri sendiri).

Parikan yang diucapkan tersebut untuk menyindir bahwa para tetangga pada komentar karena sebuah keluarga yang mencari makan sendiri-sendiri atara suami dan istri. Bentuk parikan-parikan tersebut sering dijumpai dalam pertunjukan ludruk di Daerah Jawa Timur utamanya Jombang di mana kesenian Ludruk masih hidup. Para Sehu yang berasal dari Jombang telah akrap dengan gaya parikan-parikan dalam ludruk sehingga mereka membuat dan menyelipkan disela-sela dialog tokoh santai seperti tokoh Book Ing dalam pertunjukan Potehi.

(2) "Tuku Bolah Kok Ireng

Jare Sekolah Kok meteng"

(beli benang kok warna hitam

Katanya sekolab kok malah hamil duluan)

Parikan tersebut sebetulnya menyindir gadisgadis remaja sekarang yang berkelakuan kurang baik, sehingga sering didapati mengalami $M B A$ (Marriage ByAccident) atau menikah terpaksa diusia dini karena " kecelakaan " (hamil terlebih dulu). Namun sering para Sehu tidak sampai hati mengucapkan kata-kata "meteng" (hamil) makasering diplesetkan "Tuku bolah kok ireng, jare sekolah Kok...Ireng... (penonton tertawa karena sudah tahu maksudnya).

\section{(3). Kupat janure tuwo}

Kula lepat nyuwun sepuro

(Ketupat janurnya tua

Saya salah minta maaf)
Parikan ini biasa dipakai orang Jawa pada saat bulan syawal untuk saling memaafkan, namun sering pula dipake di luar bulan syawal untuk meminta maaf. Mengingat para sehu merupakan orang-orang Jawa dan Muslim, parikan ini sudah lekat dengan mereka. Kata sepuro (mintamaaf) merupakandialek Jawa Timuran yang berbedadengan DIY \&Jawa Tengah yang berdialekpangapura untuk menyebut kata yang sama.

(4). Manuk glathik nisil pari, mabur lima teka telu

Luwih becik netepi janji Luwih elek janji palsu

(Burung gelatik makan padi, terbang lima datang tiga

Lebih baik memenuhi janji, lebih jelek janji palsu)

Parikan ini membuat celetukan dari para penonton, karena digiring pada asumsi janji palsu tersebut bisa pada hubungan percintaan, bisa masalah pelunasan hutang piutang $\mathrm{d} s \mathrm{~b}$.

\section{(5). Suwe ora jamu, jamu godong kara}

Suwe gak ketemu ketemu pisan dadi perkara.

Parikan ini sudah dipopulerkan dalam bentuk lagu dengan judul Suwe Ora Jamu. Syair lagu tersebut sering diganti-ganti sesuai dengan kebutuhan. Sebagaimana halnya parikan di atas membuat suasana menjadi gayeng(seru) karena persoalan mengarah pada PIL atau WIL, persoalan yang paling membuat orang tertarik.

\section{Penutup}

Teater Boneka Tiongkok terdapat beberapa jenis hampir sama dengan yang dimiliki Indonesia khususnya jenis wayang (Boneka Bayangan) dan wayang golek (boneka tiga dimensi dari kayu). Namun demikian justru yang menyebar ke wilayah Indonesia adalah wayang golek jenis Boneka tali (Marionett) atau di sebut wayang Gantung di Kalimantan Barat dan Boneka Kantong Tangan (Glove Puppet) yang populer dengan sebutan wayang Potehi di wilayah Jawa. Sedangkan untuk wayang Cinwa (China-Jawa) sebutan wayang ciptaan Gan Thwan Sing sifatnya personal dalam arti di ciptakan dan dimainkan oleh Gan Thwan Sing sendiri, tidak ditemukan dalang lain yang memainkan dan tidak terdapat di daerah lain. Ketika beliau wafat sudah tidak ada yang melanjutkan. 
Wayang Potehi dan Wayang Gantung demikian sebutan populer di masyarakat telah menjadi bagian budaya masyarakat di Indonesia.Karena itu sudah selayaknyamendapat perhatian lebih seksama dari masyarakat luas utamanya pelaku dan pemerhati seni.

\section{Kepustakaan}

Brandon, James R. 1993. The Cambridge Guide to Asian Theater. USA: Cambridge University Press.

Cohen, Alvin P. 1981. "A Taiwanese Puppeteer And His Theatre." Source: Asian Folklore Studies, Vol. 40, No. 1. 1981. pp. 33-49. Published by: Nanzan Institute for Religion and Culture.

Gie, Tio Tiong,(2005). "Empat Narapidana" dalam Gong No. 67 /VI/2005.

Haryono, Timboel. 2004. Seni Pertunjukan Pada Masa Jawa Kuno. Yogyakarta: Pustaka Raja.

HT, Faruk,, Bakdi Soemanto, 7 Bambang Purwanto, (2000), Perlawanan Atas Diskriminasi Rasial-etnik, Konteks sosial idiologis Kritik Saatra Tionghoa Peranakan. Magelang: Indonesia Terra.

Jilin, Liu. 1988. Chinese Shadow Puppet Plays. Beijing: Morning Glory Publishers.

Kayam, Umar,(1981), Seni, Tradisi, Masyarakat. Jakarta: Sinar Harapan.

Kemp, E.G. The Face of China. London: Chatto Windus.

Knighton, Anthony. 2007. Images of China. London: Bounti Books.

Kuardhani, Hirwan. 2003. "Seni Tionghoa Peranakan: dari Teater Boneka Potehi. Hingga Legenda Dampo Awang” Laporan Penelitian. Jakarta: ATL.
2011. ToniHarsono Maecenas Potehi

Dari Gudo. Yogyakarta: IsacBook.

.2011. "Panggung Teater Boneka Potehi : SebuahKajian Semiotika”. Laporan Penelitian. Yogyakarta: Lembaga Penelitian ISI Yogyakarta.

Kwa, David. 2005. "Wayang Pouw Tee Hie: Duta Sastra Klasik China" dalam Gong No. 67 / $\mathrm{VI} / 2005$.

Lombard, Denys.,(1996), Nusa Jawa Silang Budaya, Jaringan Asia. Gramedia, Jakarta.

Mastuti, Dwi Woro Retno. 2004. "Wayang China Di Jawa Sebagai Wujud Akulturasi Budaya dan Negara Kesatuan Republik Indonesia“" makalah dalam Seminar Naskah Kuno Nusantara di PNRI, Jakarta.

Mulyono, Sri. 1982. Wayang Asal-usul, Filsafat dan Masa Depannya. Jakarta: Gunung Agung.

Salmon., Claudine S. 1985. Sastra China Peranakan. Jakarta: Balai Pustaka.

Stalberg, Roberta Helmer. 1984. China's Puppet. San Francisco: China Books.

Soedarsono.,RM, (2005). "Didik Nini Thowok dan Perkembangan Seni Pertunjukan China" dalam GR Lono Simatupang. (ed). Cross GenderDidik Nini Thowok. Sava Media: Malang

Yeh, Tsao Pen. 1986. "Puppet Theatre In Hongkong". University Press: Hongkong

Yimin, Chen \& Liu Jun Xiang. (ed). 1999.Chinese Quyi,Acrobatics Puppetry and Shadow Theatre. Culture and Art Publishing House: Beijing

Yuanzhi,Kong. 2005.Silang Budaya Tiongkok Indonesia. PT. Bhuana Ilmu Populer-Kelompok Gramedia: Jakarta. 